\title{
Larvicidal Effect of Vinca Fruit Extract (Vinca rosea) against Aedes aegypti Larvae and Secondary Metabolites Profile by Thin Layer Chromatography
}

\author{
Rahmawati Ekaputri ${ }^{1}$, Sudarsono ${ }^{1 *}$ and Budi Mulyaningsih ${ }^{2}$ \\ ${ }^{1}$ Department of Pharmaceutical Biology, Faculty of Pharmacy; ${ }^{2}$ Parasitology Laboratory, Faculty of Medicine, UGM, Indonesia \\ Author correspondency*: \\ sudarsono@ugm.ac.id
}

\begin{abstract}
Background: Vinca rosea is known contain alkaloids, it was usually used to treat various diseases. Alkaloids from Vinca leaves are also already known have larvicidal activity. Based on this toxicological activity, the fruit of Vinca rosea was selected to investigation its larvicidal activity against the $3^{\text {rd }}$ instar larvae of the mosquito vector of dengue haemorrhagic fever (DHF) Aedes aegypti. Five concentrations of Vinca fruit extract were tested against the $3^{\text {rd }}$ instar Aedes aegypti larvae. The different larval mortality percentages were recorded after 24 hours. Lethal concentration $\left(\mathrm{LC}_{50}\right.$ anf $\mathrm{LC}_{90}$ ) of Vinca fruit extract were calculated using Probit analysis. Phytochemical compounds of ethanolic extract also investigated using Thin layer Chromatography (TLC). LC 50 and LC 90 values of fruit extract were 2.987 $\mathrm{mg} / \mathrm{ml}$ and $32.861 \mathrm{mg} / \mathrm{ml}$. Alkaloids were detected in extract.
\end{abstract}

Keywords: larvicidal activity, Vinca rosea, Chromatography, secondary metabolites, Aedes aegypti

\section{Introduction}

Aedes aegypti transmit a number of diseases, such as filariasis, chikungunya, and dengue haemorrhagic fever (DHF). DHF causing millions of deaths every year. The only way of reducing the incidence of this disease is by vector control using synthetic insecticide. The synthetic insecticide are more hazardous to handle and not biodegradable. Substances alternative of chemical pesticides, which pollute and threaten future, can be discovered. More than 300 plant species have been reported to have an activity against mosquitoes included Vinca leaves extract (Remia and Logaswany, 2011).

Vinca rosea (Fam.Apocynaceae) is plants grow everywhere in Indonesia (Fig. 1). Vinca rosea has more than 120 indol alkaloids and another alkaloids in the whole plant (Van der heijden et al., 2004). The present study was carried out to determine the larvicidal activity of Vinca rosea fruit extract against Aedes aegypti larvae.

\section{Methodology \\ Preparation and extraction of plant materials}

The fruits of Vinca rosea were collected as wild plants at "north Sekip" at Yogyakarta. Indonesia. Fruits were identified at Department of Pharmaceutical Biology Faculty of Pharmacy, UGM Yogyakarta. Voucher specimen was found at this Department. Fruits were washed and dried at $40^{\circ} \mathrm{C}$ for 12 hours. $370 \mathrm{~g}$ dried fruit powder was macerated with $2.5 \mathrm{~L}$ of ethanol $(96 \%)$ for 48 hours. The ethanol was then evaporated to sticky residues. The extract residue was $6.95 \% \mathrm{~b} / \mathrm{b}$ and kept in the refrigerator.
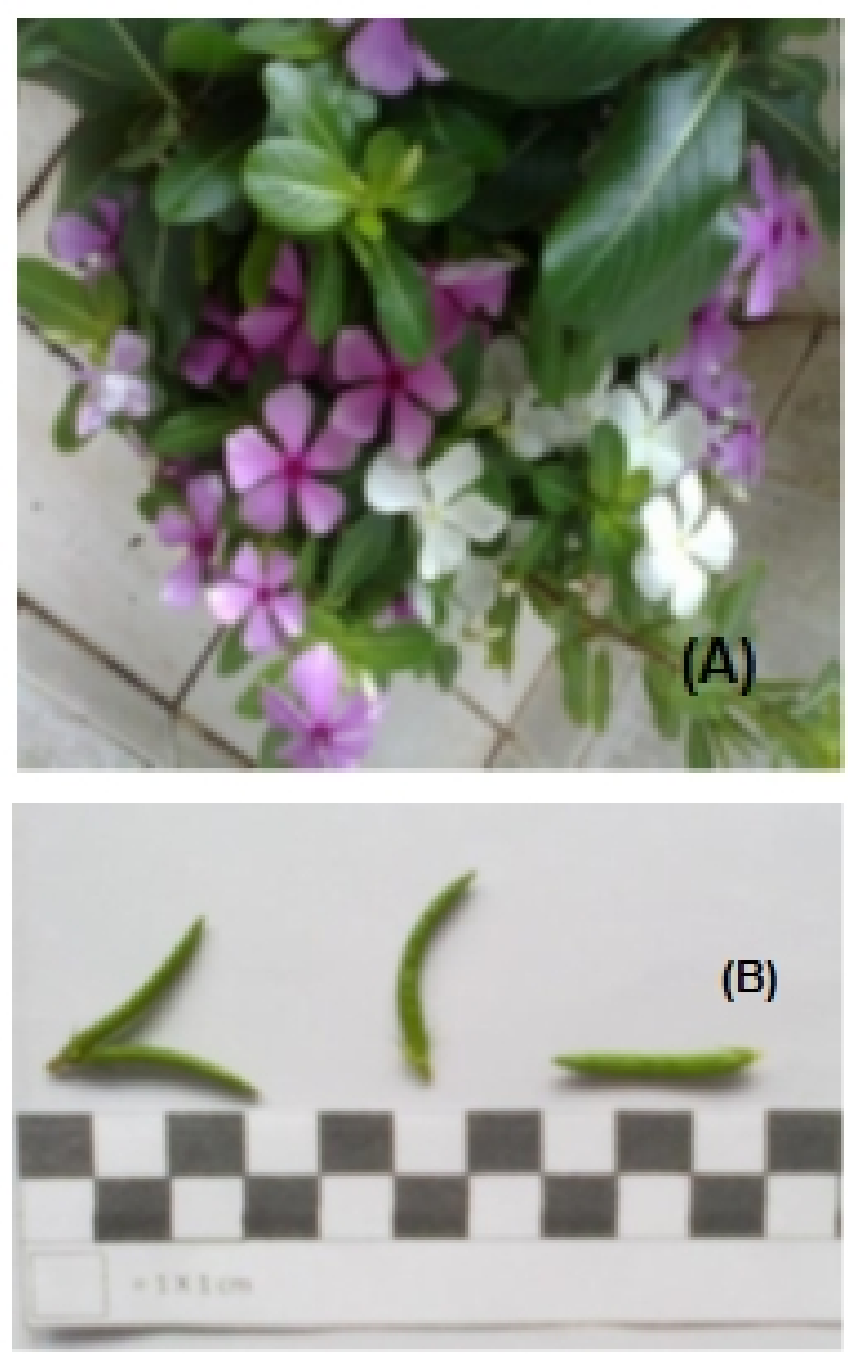

Figure 1. (A) Vinca rosea (B) Fruit of Vinca rosea. 


\section{Bioassay for larvicidal toxicity}

Different concentrations of extract $(0.4 \mathrm{mg} / \mathrm{mL}, 0.8$ $\mathrm{mg} / \mathrm{mL}, 1.6 \mathrm{mg} / \mathrm{mL}, 3.2 \mathrm{mg} / \mathrm{mL}$, dan $6.4 \mathrm{mg} / \mathrm{mL}$ ) were prepared using boiled distilled water. Bioassay were performed according to standard method (WHO, 2005). Twenty five $3^{\text {rd }}$ larvae of Aedes aegypti were introduced in different test concentration with a set of control containing distilled water and water without test solution. The glass with the larvae, were kept at room temperature. After 24 hours of exposure, the number of dead larvae were counted to obtained mortility rate. Three replications were maintained for each concentration. Larval mortality were counted after 24 hours.

The $\mathrm{LC}_{50}$ and $\mathrm{LC}_{90}$ were calculated according to Probit methods of Finney (Finney, 1971). The concentrations in probit analysis were transformed to logarithm (Log concentration) and the lethal concentrations $\left(\mathrm{LC}_{50}\right.$ and $\left.\mathrm{LC}_{90}\right)$ were calculated manually.

\section{Thin Layer Chromatography}

Secondary metabolite compounds of Vinca fruit extract was analyzed by Thin Layer Chromatography (TLC) and the spot visualitasion was by the spray reagents. Chromatography was perfomed using aluminium plates precoated with silica gel $60 \mathrm{~F}_{254}$ (E.Merck). Extract solution was prepared by dissolving it in ethanol pro analysis. One microliters of the extract solution was applied to the plate. Plates were developed face-down, to a distance of $8 \mathrm{~cm}$, in a glass chamber after conditioning until saturated with mobile phase vapor. Mobile phase that used was ethyl acetate: methanol $(9: 1 \mathrm{v} / \mathrm{v})$. After development the mobile phase was evaporated to dryness and plates were sprayed with Dragendorff's and ninhidrin reagent.

Table 1. Results of probit analysis of vinca fruit extracts against larvae of Ae. Aegypti.

\begin{tabular}{|c|c|c|c|c|c|}
\hline $\begin{array}{c}\text { Extract concentration } \\
(\mathrm{mg} / \mathrm{mL})\end{array}$ & $\begin{array}{c}\text { Percentage larval mortility } \\
\text { (mean) }\end{array}$ & Probit value & $\begin{array}{c}\text { The linear regression } \\
\text { equation }\end{array}$ & $\begin{array}{c}\mathrm{LC}_{50} \\
(\mathrm{mg} / \mathrm{mL})\end{array}$ & $\begin{array}{c}\mathrm{LC}_{90} \\
(\mathrm{mg} / \mathrm{mL})\end{array}$ \\
\hline 0,4 & $21 \%$ & 4,19 & \multirow{5}{*}{$\begin{array}{c}\mathrm{Y}=1,229 \mathrm{X}+4,416 \\
\quad \text { with } \mathrm{R}=0,910\end{array}$} & \multirow{5}{*}{2,987} & \multirow{5}{*}{32,861} \\
\hline 0,8 & $21 \%$ & 4,19 & & & \\
\hline 1,6 & $27 \%$ & 4,39 & & & \\
\hline 3,2 & $44 \%$ & 4,85 & & & \\
\hline 6,4 & $76 \%$ & 5,17 & & & \\
\hline
\end{tabular}

\section{Results and Discussions}

\section{Larvicidal effect of Vinca fruit extract}

The $24 \mathrm{~h}$ bioassay is a major tool for evaluating the toxical effect of vinca fruit extract against Aedes aegypti larvae. The mosquito larvae exposed under plant extract showed significant behavior changes. The larvae showed restlessness, loss of equilibrium, and led to death. Dead larvae are those that cannot be induced to move when they are probed with a needle in the siphon or the cervical Region (WHO, 2005).

In table 1 the 5 concentrations of Vinca fruit extract caused larval mortality of $21 \%, 21 \%, 27,44$, and $76 \%$. Zero percent of mortality was noted in control. $\mathrm{LC}_{50}$ and $\mathrm{LC}_{90}$ calculated were $2.987 \mathrm{mg} / \mathrm{mL}$ and $32.861 \mathrm{mg} / \mathrm{mL}$.

The larvicidal activity shown by Vinca rosea is probably due to the presence of the alkaloid which are toxic substances. Phenolic and non-phenolic alkaloids isolated from Vinca rosea leaves are known to have toxic effects (Waskito, 1999).

\section{Phytochemical compound of Vinca Fruit Extract}

Zones with $R_{f} 0.33-0.39$ gave positive results after being sprayed with

Dragendorff's reagent and gave negative results after being sprayed with Ninhydrin reagent $\left(R_{f} 0.33\right)$ That was mean no amino acid spot detected (Fig. 2).
Positive results with Dragendorff reagent will give orange-red spots or brown with orange background yellow (Wagner and Bladt, 1996).

A positive result with Ninhydrin reagent appeared after heating $95-120^{\circ} \mathrm{C}$ about 10 minutes (Jork et al., 1990). Samples containing amino acids will give a positive spots that appear blue-violet.

Tryptophan is the precursor indole alkaloid biosynthesis is a major component of plant alkaloids in Vinca rosea (Tikhomiroff and Jolicoeur, 2002). Spraying with Ninhydrin is used to ensure that the zones $R_{f} 0.33$ 0.39 are alkaloids. After isolated brown zones showed the presence of alkaloid compounds in the fruit extract vinca rosea $\left(R_{f} 0.33\right)$.

The result of vinca fruit extract was also proved that they had larvicidal properties against Aedes aegypti larvae. Nelson et al., (2006) reported that the whole $V$. rosea plant is poisonous. Whole plant Vinca rosea also has a toxic effect on the larvae of Artemia salina (brine shrimp) (Gadir, 2012 dan Rahmatullah, 2010). The larvicidal properties exhibited by vinca extract in this study might be related to presence of vinca alkaloids toxins in the plant.

\section{Conclusion}

The present study has demonstrated that an ethanolic extract of vinca fruit had capability as larvicides against 
Aedes aegypti larvae. Further studies are needed to determine the marker compound for producing Standard Operating Procedure (SOP) and to study their impacts on human health and non-target organisms in mosquito feeding habitats.

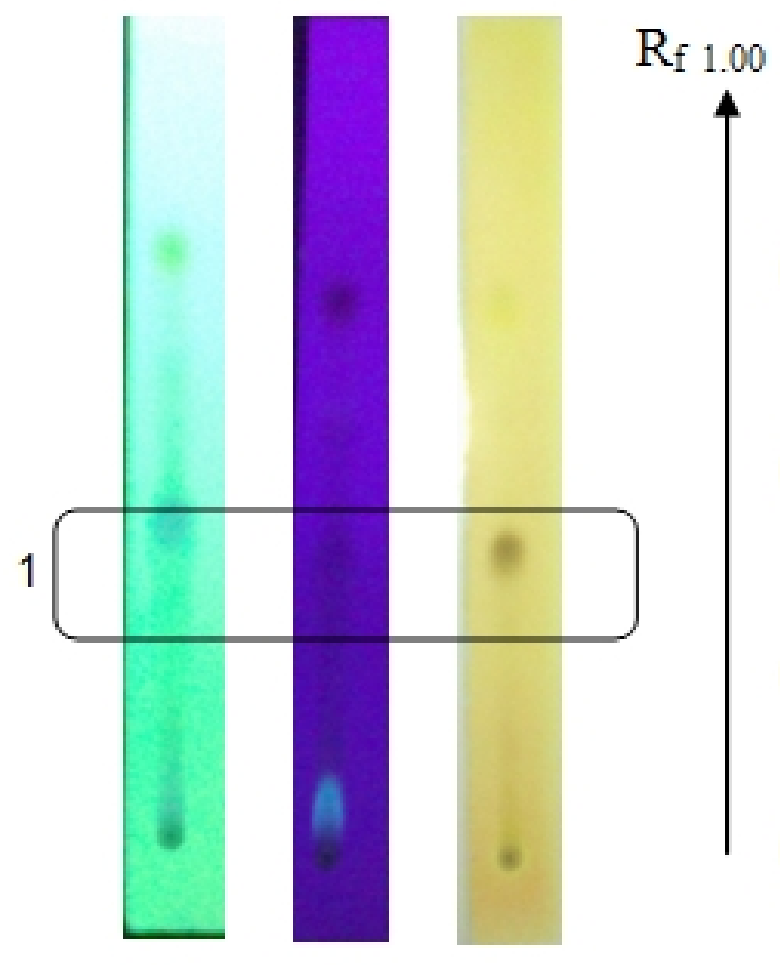

(A) $\quad(B)$

(C)

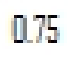

0.50

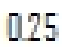

0.00

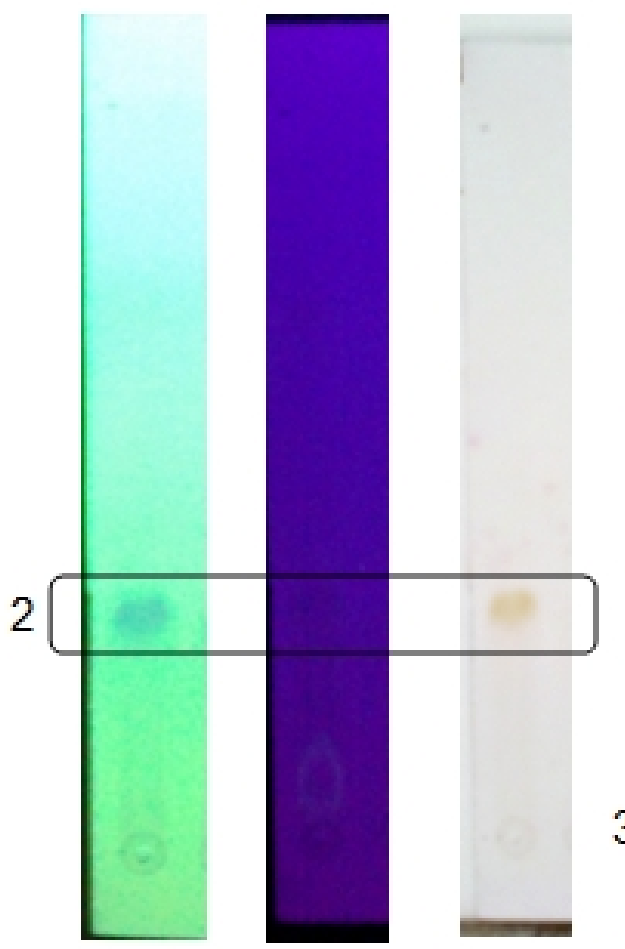

(A)

(B)

(D)

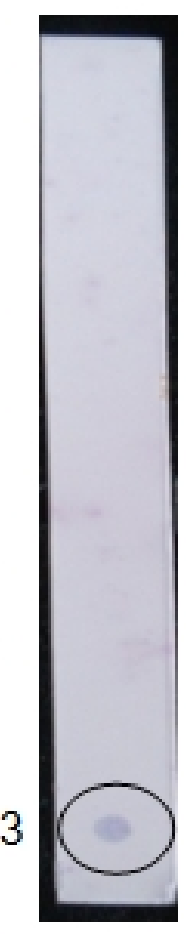

(E)

Figure 2. Chromatogram of Vinca fruit ethanolic extract. Solvent systems: ethyl acetate-methanol (9:1 v/v). Detection (A) UV-254nm, (B) UV-365nm, (C) Dragendorff's reagent, (D) ninhydrin reagent, (E) reference for positive result with Ninhydrin reagent: yolk. (1B) alkaloids and another compounds with nitrogen shows fluorescence in UV-365 and (1C) react as brown zones with Dragendorff's reagent $\left(R_{f} \sim 0.33-0.39\right)$. $(2)$ Brown zones indicated negative result with ninhydrin reagent $\left(R_{f} \sim 0.33\right)$. (3) Amino acids react as blue-violet zones with Ninhydrin reagent.

\section{Acknowledgment}

I would like to thank to Faculty of Pharmacy UGM for the permission for doing this experiment.

\section{References}

Gadir, A. (2012). Assement of Bioactivity of Some Sudanese Medicinal Plants using Brine Shrimp (Artemia salina) Lethality Assay. Journal of Chemical and Pharmaceutical Research 4 (12): 5145-5148.

Jork, H., Funk, W., Fischer, W. \& Wimmer, H. (1990). Thin-Layer Chromato-graphy: Reagents and Detection Methods Volume 1a. VCH. New York.

Nelson, L. S.; R. D. Shih and M. J. Balick. (2006). Handbook of Poisonous and Injurious Plants $2^{\text {nd }}$ edition. Springer: 340.

Rahmatullah, M., Sadeak, I., Bachar, C., Hossain, T., Abdullah, Montaha, Jahan, N., Chowdhury, M., Jahan, R., Nasrin, D., Rahman, M. \& Rahman, S. (2010). Brine Shrimp Toxicity
Study of Different Bangladeshi Medicinal Plants, Advances in Natural and Applied Sciences 4: 163-173.

Remia, K.M. \& Logaswany, S. (2009). Larvicidal Efficacy of Leaf Extract of Two Botanicals Against the Mosquito Vector Aedes aegypti (Diptera: Culicidae). Indian Journal of Natural Products and Resources 1(2): 208-212.

Tikhomiroff, C. \& Jolicoeur, M. (2002). Quantification of Indole Alkaloids and Iridoid Precursors in Catharanthus roseus Hairy Roots by High-Performance Liquid Chromatography. Journal of Chromatography A 955: 87-93.

Van der Heijden, R., Jacobs, D.I., Snoeijer, W., Hallard, D. \& Verpoorte, R. (2004). The Catharanthus Alkaloids: Pharmacognosy and Biotechnology, Current Medicinal Chemistry 11(5): 607-628.

Waskito, T. (1999). Isolasi dan Uji Aktivitas Alkaloid dari Daun Tapak Dara (Catharanthus roseus) var albus., Tesis, Universitas Diponegoro. Semarang.

WHO. (2005). Guidelines for Laboratory and Field Testing of Mosquito Larvicides, WHO Communicable Disease Control, Prevention and Eradication. WHO Pesticide Evaluation Scheme. Geneva. 
